\title{
A-TVDBR: Um Modelo de Atividades para TV Digital Brasileira
}

Title: A-TVDBR: An Activity Model for Brazilian Digital TV

\author{
MOZART DE MELO ALVES JÚNIOR \\ Mestrado em Modelagem Computacional de \\ Conhecimento \\ Instituto de Computação \\ Universidade Federal de Alagoas (UFAL) \\ mozart@kmf.com.br
}

\author{
ARTURO HERNANDEZ DOMINGUEZ \\ Mestrado em Modelagem Computacional de \\ Conhecimento \\ Instituto de Computação \\ Universidade Federal de Alagoas (UFAL) \\ arturohd@uol.com.br
}

Resumo Este trabalho propõe um modelo de atividades de aprendizagem para TV Digital Brasileira (ATVDBR) possibilitando, de forma ativa e principalmente interativa, o aprendizado e a formação através da TV Digital, tendo como público alvo os alunos portadores de deficiências físicas e que possuem limitação motora da associação dos deficientes físicos do estado de Alagoas (ADEFAL). O modelo foi especificado e implementado para GINGA-NCL, utilizando-se da linguagem declarativa NCL (Nested Context Language). Foi realizado um curso para deficientes físicos que possuem limitação motora. Os resultados obtidos mostram que os alunos que usaram a TV-Digital obtiveram um melhor desempenho que os alunos que usaram um ambiente virtual de aprendizagem com o mesmo conteúdo.

Palavras-Chave: TV Digital,Modelo de atividades de aprendizagem, AVA, GINGA, NCL, portadores de deficiências físicas

\begin{abstract}
This paper presents a Digital TV Learning Activities Model (A-TVDBR) that allows interactive learning and teaching activities on Digital TV. The target audience is students with motion restrictions of the association of the disabled of Alagoas state (ADEFAL). The model was designed and implemented using GINGA-NCL (Nested Context Language). It was executed a course for disabled people who have limited mobility. The results show that the students of the Digital TV group had better performance than the students of the Virtual Learning Environment group, the same course content was used with the two groups of students.
\end{abstract}

Keywords: Digital TV, Learning Activities Model, Learning Management System, GINGA, NCL, users with motion restrictions 


\section{Introdução}

De acordo com CASTRO [5], o qual teve como parâmetro uma pesquisa realizada pelo IBOPE em 2007, os brasileiros ficam diariamente em média 5 horas, 5 minutos e 52 segundos com o televisor ligado; também segundo outra pesquisa, TIC Domicílios [15], cerca de 98\% das residências brasileiras possuem, pelo menos, um aparelho de televisão em seus lares. Isso nos mostra que a $\mathrm{TV}$, comparada com qualquer outra tecnologia da informação e de comunicação (TIC), consegue atingir quase que a totalidade de todas as camadas sociais.

Dados como esse corroboram que vivemos em um país onde a televisão é o meio de comunicação e entretenimento mais utilizado.

Pensando nas possibilidades que a TV possa trazer para sociedade, o Sistema Brasileiro de TV Digital (SBTVD), instituído em 23 de novembro de 2003, através do decreto $\mathrm{n}^{\circ} 4.901$ [4], teve como finalidade proporcionar a interatividade e o desenvolvimento de novas aplicações que ofereçam entretenimento à população, promovendo a educação, a cultura, e a inclusão social [6]. Dessa forma, não serão discutidas, apenas, implicações técnicas, como alta definição e técnicas de compressão, mas também será tratada a TV Digital como um fator de promoção à inclusão social, através de serviços públicos, educação a distância e diversas outras oportunidades que surgem com essa nova plataforma no país.

É necessário que o Brasil deixe de pensar em TV Digital apenas como melhoria de imagem e som, para que sejam iniciados os processos de viabilização da interatividade, para então termos, de fato, uma TV Digital que possibilite a diminuição de barreiras sociais, viabilizando o ensino e aprendizado para todos, não apenas para alguns. De acordo com BATISTA [3], a TV digital interativa pode ser definida como a fusão da TV tradicional com as tecnologias de informática, permitindo que os telespectadores participem ativamente dos programas que assistem, com a possibilidade de interação com o conteúdo. VICARI e SILVIA [18] afirmam que a partir do advento da televisão digital interativa no Brasil, percebeu-se que ela pode ser um recurso de grande potencialidade educacional

Já o termo AVA (Ambientes Virtuais de Aprendizagem) é conceituado por VAVASSORI e RAABE [16] como um sistema que reúne uma série de recursos e ferramentas que permitem suas utilizações em atividades de aprendizagem através da Internet em um curso à distância. Atualmente, os AVA desenvolvidos pela Web tornaram-se ambientes de aprendizado muito difundidos, pois com a evolução da internet, essa forma de ensinar tornou- se bastante aceita e utilizada. VERAS[17] afirma que através da EAD, consegue-se prover ensino a uma maior quantidade de pessoas, inclusive para aquelas que vivem em regiões muitas vezes inacessíveis pela educação tradicional como também para as que não tem tempo para se deslocar a uma instituição de ensino.

Apesar do alto grau de utilização dos Ambientes Virtuais de Aprendizagem na web, algumas limitações são detectadas como: quantas pessoas têm condições financeiras de possuírem um computador e internet em seus domicílio para viabilizar essa forma de aprendizagem? Sabemos que para utilizar um AVA esses itens são indispensáveis. Mas quantos brasileiros possuem um computador em casa? De acordo com a pesquisa TIC Domicílios [15], enquanto $98 \%$ das residências brasileiras possuem pelo menos um aparelho de televisão em seus lares, apenas $24 \%$ dos domicílios possuem um computador, e destes apenas $8 \%$ é da classe D. É através de dados como esses que se pode concluir que a população brasileira possui um alto grau de aceitação em relação à TV. Boa oportunidade para que se possa utilizar essa tecnologia no ensino, de forma que atenda a todas as camadas da população.

$\mathrm{O}$ artigo apresenta um novo modelo de atividades (A-TVDBR) para o contexto da TV Digital Brasileira, possibilitando através, da interatividade, a inclusão social e a formação das pessoas que, por algum motivo, possuam limitações motoras. O modelo proposto permitirá a participação dessas pessoas de forma ativa e, principalmente, interativa dentro de seu próprio lar, viabilizando o aprendizado e a formação on-line através do uso da TV Digital Brasileira.

\section{Trabalhos correlatos}

Nesta seção, serão abordadas algumas aplicações que fazem uso da TV Digital Interativa com a finalidade educacional no Brasil e no mundo.

\subsection{TV Escola Digital Interativa}

Lançado em fevereiro de 2004 no canal do Ministério da Educação e pela Secretaria de Educação a Distância, a TV Escola, já tinha como principal objetivo ser um apoio pedagógico principalmente para os educadores. No caso da TV Escola Digital Interativa, esse objetivo se torna mais efetivo, já que eles podem ter acesso, além do conteúdo audiovisual, a outros materiais como tabelas, textos, gráficos e ilustrações. Já o conteúdo interativo fica por conta da possibilidade da realização de cursos, provas, recebimento de material didático, envio de sugestões 
e prática de consultas junto ao Ministério da Educação, como visto na Figura 1[11].

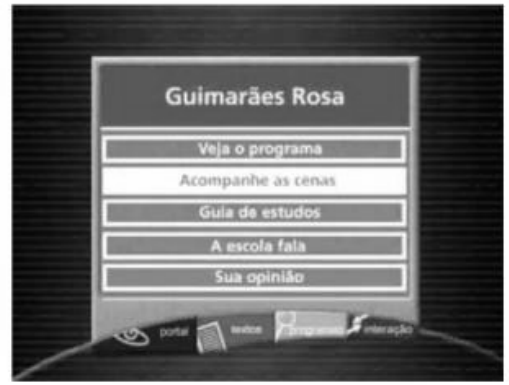

\subsection{O projeto InteraTV}

De acordo com ANDREATA [1], o projeto foi desenvolvido pela Universidade Federal de Santa Catarina,. O mesmo apresenta um portal para TVD que emprega aplicações colaborativas na área educacional, propondo seu uso em um cenário de ensino à distância (Figura 2). Além disso, utiliza o ambiente de desenvolvimento do padrão do middleware europeu, o MHP, baseado na linguagem Java.

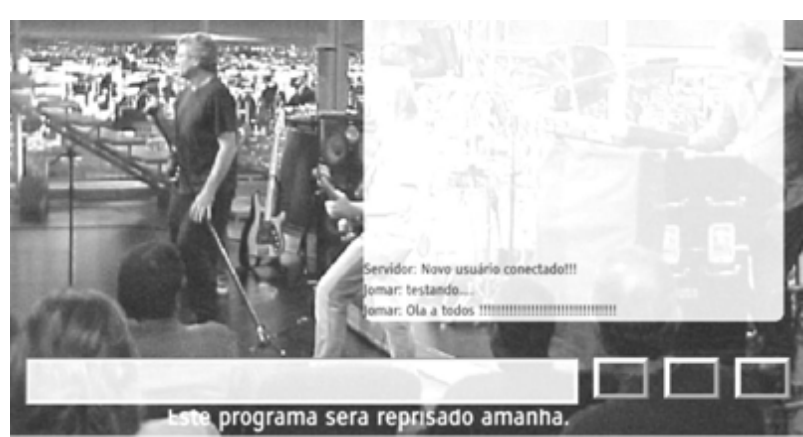

Figura 2: Protótipo do InteraTV com aplicação de chat e teletexto em

\subsection{SOS Teacher (SOS Professor).}

Sistema desenvolvido no nordeste da Inglaterra na cidade de Kingston (Figura 3), onde um canal disponibilizado pela KIT - Kingston Interactive Television - o colocou no ar em parceria com a BBCi. Ele é dedicado à realização do reforço escolar. A comunicação entre o estudante e o professor é feita através do Set Top Box, ou seja, o estudante envia o material que está com dúvidas e o professor retorna assim que responde. Esse tipo de comunicação só é permitido na TV digital para promover educação [8].
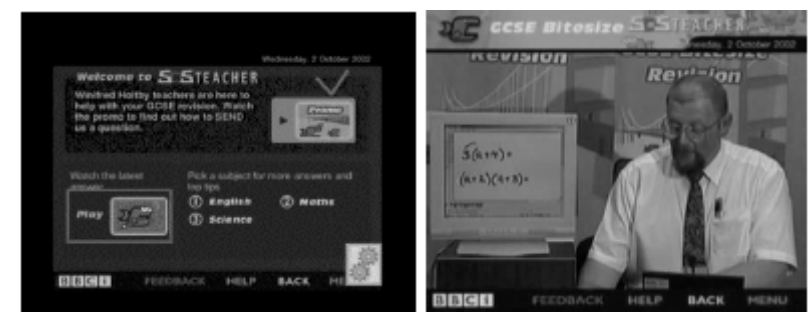

Figura 3: Promovendo reforço escolar através do T-learning

\subsection{Projeto Turma da árvore:}

De acordo com Tavares [14], o programa projetado (Figura 4) e produzido inicialmente pela Universidade de Salvador para TV convencional é um artefato dirigido ao público infantil que aborda assuntos transversais, como cidadania e meio ambiente em histórias vividas por bonecos animados. A intenção do programa, além de educar "brincando", é servir de ferramenta de apoio em sala de aula aos professores de educação infantil.

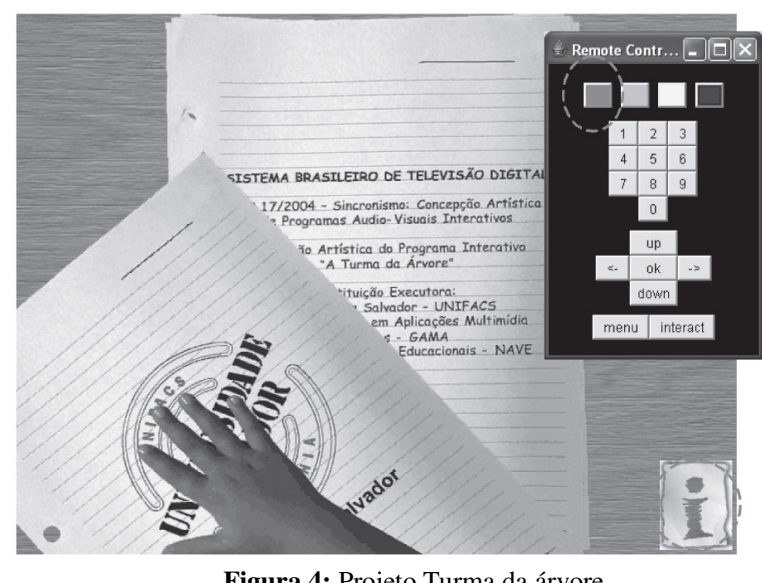

Todas as aplicações para TV Digital, descritas anteriormente, possuem preocupações no que tange a educação a distância, da mesma forma será apresentado um novo modelo que vise possibilitar a aprendizagem através da TV Digital Brasileira. 


\section{Modelo de Atividades On-line}

Dentre os modelos existentes sobre a implementação de atividades em AVA, um dos modelos mais referenciados na literatura é o modelo de cinco etapas (Figura 5) proposto por Salmon [12]. Neste modelo, a aprendizagem acontece de forma gradual, na medida em que a interação acontece entre os participantes durante o desenvolvimento das etapas.

Fundamentalmente, o modelo contempla estágios que devem ser desenvolvidos pelos professores na elaboração de suas atividades em AVA, como também as atividade do moderador do processo de ensino-aprendizagem.

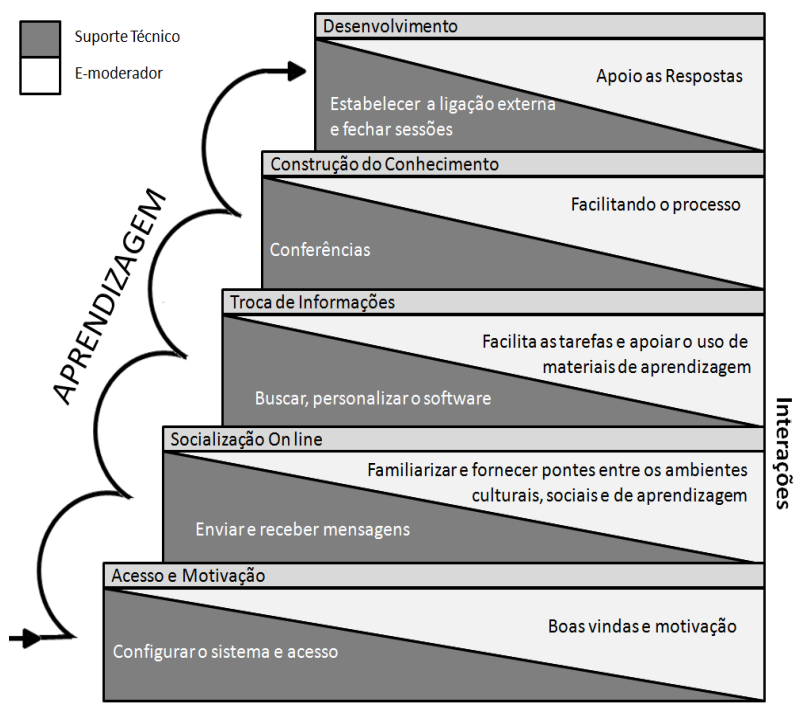

Figura 5: O modelo de atividades on-line no contexto de um AVA.

De acordo com a Figura 5, cada etapa requer que os participantes possuam e dominem certas habilidades técnicas; o que é expresso na parte inferior esquerda. Cada etapa exige diferentes habilidades aos moderadores; o que é expresso na parte superior direita de cada estágio. Segundo Salmon[12], este modelo mostra como motivar os participantes on-line e como construir o aprendizado través das atividades apropriadas. O modelo é dividido em cinco etapas: acesso e motivação, socialização online, troca de informação, construção do conhecimento e desenvolvimento.

\section{Modelo Proposto para TV Digital}

Diante da realidade brasileira no contexto da TV Digital, é necessário propor várias adaptações ao modelo consolidado de cinco etapas de Salmon, uma vez que o mesmo está direcionado para um ambiente web, contudo a proposta deste trabalho abrange apenas a TV Digital.

Uma das adaptações proposta pelo novo modelo denominado A-TVDBR deverá ocorrer em tempo de cons- trução do modelo, tratando do desenvolvimento das atividades no ambiente da TV Digital interativa, baseado no middleware Ginga NCL [Ginga 2008], onde o aluno irá, de fato, interagir com as aplicações interativas e vídeos em tempo real.

\subsection{O Modelo A-TVDBR}

O modelo A-TVDBR (Figura 6) propõe possibilitar ativa e interativamente o aprendizado e a formação online através do uso da tecnologia de TV Digital.

Cada atividade deve ser relacionada ao domínio da disciplina e baseada na utilização de recursos (vídeo, material didático, links externos, acesso a banco de dados entre outros) para sua execução, necessitando, os participantes, de apoio durante a realização das atividades. De forma similar ao modelo de Salmon [13], o A-TVDBR, é representado por cinco etapas que conduzem, progressivamente, os participantes a uma aprendizagem no contexto de uma formação on-line através do uso da TV Digital. Cada etapa requer atividades de diferentes naturezas, apropriadas para a motivação dos participantes e construção conseqüente da aprendizagem.

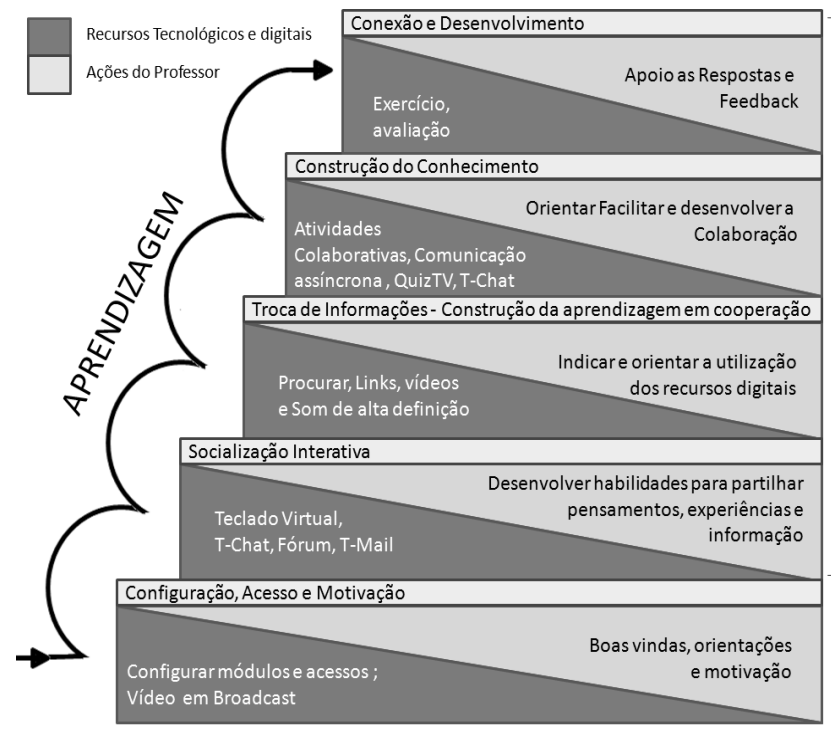

Figura 6: O modelo de atividades A-TVDBR no contexto da TV Digital.

\subsubsection{Configuração, Acesso e Motivação}

Nessa etapa, é de suma importância que o sistema esteja plenamente configurado, por se tratar de uma aplicação para TV Digital. Nessa configuração, deverá conter o que será visto, quem terá acesso, quando será disponibilizado e quais atividades produzidas serão exibidas na TV Digital. Caberá ao professor configurar esse módulo, de 
tal forma que, em determinado dia e horário, a aplicação em Ginga NCL [7] seja disponibilizada pelas emissoras, e transmitidas aos set-top-box1 .

Além das configurações dos recursos tecnológicos a serem utilizados, faz-se necessário um controle de acesso (Figura 7) para que os participantes se sintam a vontade e sem receio de interatuar com a tecnologia oferecida. Isso deverá ocorrer através da TV, utilizando-se os recursos de vídeo via broadcast, prestando as boas vindas e, principalmente, as orientações necessárias, facilitando o entendimento de como proceder na utilização desta nova tecnologia, uma vez que a TV é algo conhecido, mas a TV Digital tem suas minúcias que são incomuns à grande população como, por exemplo, o controle remoto onde as teclas: vermelha, verde, amarela e azul serão bastante utilizadas no decorrer do aprendizado.

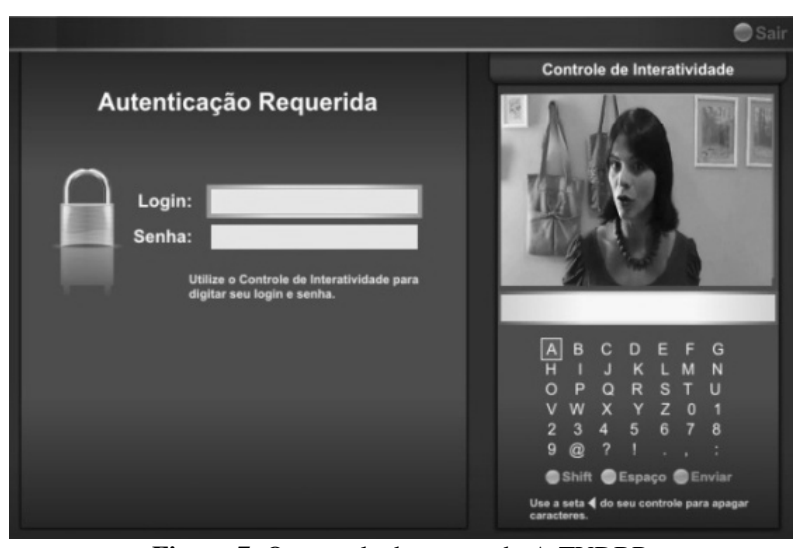

Figura 7: O controle de acesso do A-TVDBR

Nesta primeira etapa, as habilidades tecnológicas dos participantes variam enormemente, por isso se faz necessário proporcionar uma ligeira, mas interessante introdução no uso das plataformas tecnológicas, sendo primordial possibilitar o bom entendimento, a fim de não desmotivar os usuários que apresentem dificuldades em relação aos recursos tecnológicos.

Diferentemente do acesso web, onde os internautas podem fazer seus horários, a TV Digital necessita que os alunos tenham maior comprometimento nas atividades, principalmente no que tange ao cumprimento de dia e horários, pois trata-se de executar um aplicativo em um horário determinado. Para isso, deve-se pensar em vários meios de envio de mensagem, informando que determinada aula terá inicio em determinado dia e horário, a fim de que os alunos possam estar preparados para interagir.

É nesta etapa que a motivação deverá ser uma das prioridades, pois sem ela as outras etapas serão perdidas no

${ }^{1}$ É um dispositivo que converte o sinal digital em um formato que pode ser visto nas TVs analógicas tradicionais, como também a interatividade. decorrer do tempo. Salmon [13] afirma que a motivação é um aspecto significativo para o êxito da formação pois, havendo motivação, as habilidades técnicas podem ser adquiridas conforme as necessidades. Para que ocorra a motivação, é importante deixar bem claro quais são os reais objetivos de cada atividade e o princípio de cada mensagem enviada. É um grande erro pensar que os participantes vão querer dedicar horas e horas sem uma boa razão, por isso é importante, ao se criar uma atividade, estabelecer de forma clara seus objetivos e como alcançálos. Vale salientar que as atividades devem ter um nível de dificuldade gradativa, indo das mais simples, na primeira etapa, até as atividades mais complexas, nas etapas finais. Isso deve ao fato dos alunos necessitarem se ambientar com esta nova forma de aprender. Ao passar em cada etapa, novos conhecimentos são adquiridos permitindo, assim, níveis de dificuldades maiores nas elaborações das atividades. O grande objetivo da motivação, nessa etapa, é propiciar que os alunos se sintam dispostos a participar das atividades.

Com relação ao moderador, é necessário que ele seja um excelente comunicador, pois é de sua responsabilidade manter motivados os alunos, mostrando os caminhos a serem seguidos fazendo com que eles perseverem no aprendizado. Com a TV Digital, essa comunicação poderá ser uma atividade mais atrativa, pois o moderador pode se valer dos recursos de vídeo e áudio para motivar e ensinar a utilização dessa nova tecnologia, uma vez que por mais motivante que seja um texto (forma de comunicação mais utilizada na web) é uma forma de comunicação "fria", diferentemente do vídeo que possui um alto grau de aceitação. Cabe ao moderador estar preparado para interagir com esta forma diferenciada de comunicação e todas as suas possibilidades.

\subsubsection{Socialização Interativa}

Nesta etapa, é necessário que o professor possibilite, junto aos alunos, o desenvolvimento de suas habilidades para partilhar reflexões, experiências e informações. De acordo com Salmon [13], essa etapa possui o desenvolvimento de três componentes fundamentais na dinâmica das comunidades: o empreendimento conjunto (ajuda aos participantes para que compreendam as vantagens de trabalhar conjuntamente, ajudando a conhecer a forma de fazê-lo para que cada um contribua com o trabalho em grupo); a mutualidade (os participantes se conhecem e, pouco a pouco, passam a confiar um nos outros) e o repertório partilhado (implica em explorar linguagens, rotinas, sensibilidades, artefatos, ferramentas, histórias e estilos). É uma etapa base para incrementar a interação, partindo para a troca de informação e a construção do conhecimento. 
No modelo proposto, a socialização interativa será possível graças a vários recursos tecnológicos desenvolvidos neste trabalho no contexto da implementação do modelo A-TVDBR. Para a TV Digital, dentre eles, podemos citar o T-Chat, o qual permite realizar as funcionalidades de um chat na TV Digital e o T-Twitter que trata-se de um Fórum, utilizando a TV Digital. Outro recurso que pode ser utilizado será o T-Mail que funcionará da mesma forma do e-mail tradicional; sendo que o envio de mensagens poderá ser realizado através da Televisão Digital. Estas ferramentas que auxiliarão no processo de socialização utilizam o teclado virtual para TV Digital que foi desenvolvido, pensando na usabilidade das pessoas portadoras de deficiência física.

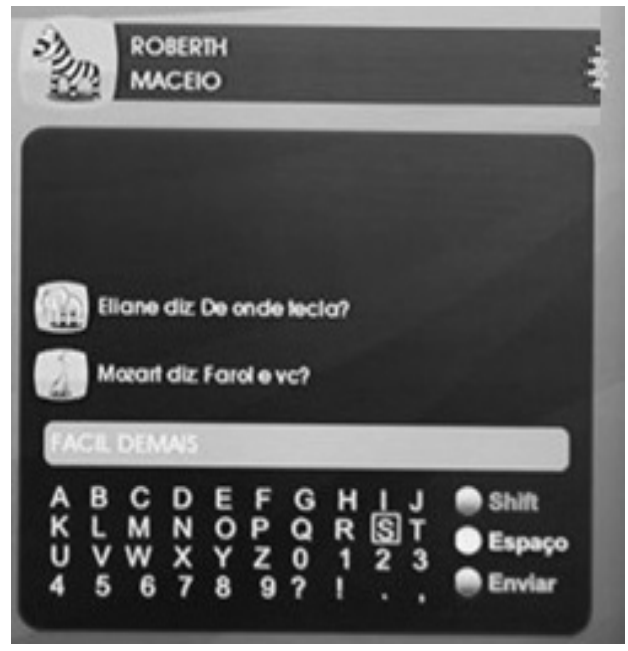

Figura 8: A ferramenta T-chat do A-TVDBR

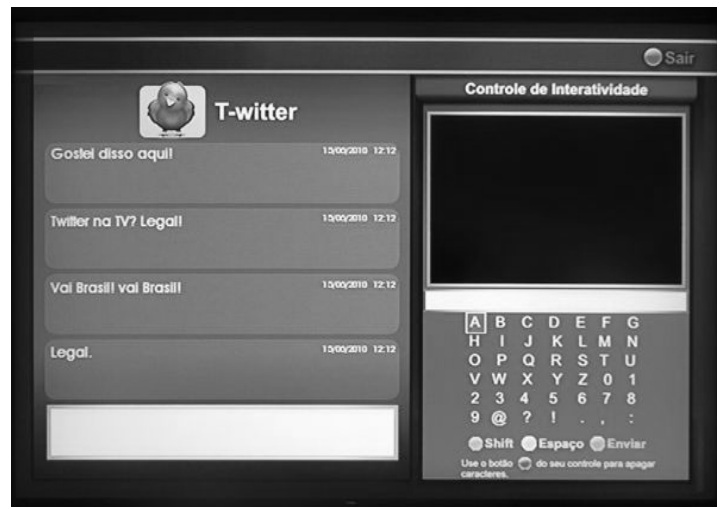

Figura 9: A ferramentas T-twitter do A-TVDBR

Vale salientar que o grande objetivo aqui é o bom uso das ferramentas que possibilitam as interações e a socialização, uma vez que se trata de uma fase onde os alunos necessitam se comunicar e as atividades, nesta etapa, devem oferecer diretamente as oportunidades de compartilhar e desenvolver o aprendizado em grupo.
Essa etapa finaliza quando os participantes começam a compartilhar entre si, estabelecendo bases para futuras trocas de informação e para a formação do conhecimento.

\subsubsection{Troca de Informações - Construção da aprendizagem em colaboração}

Nessa etapa, não basta apenas trocar informações. É necessário que as interações sejam realizadas com o intuito de construir a aprendizagem nos alunos de uma forma colaborativa, onde as interações serão realizadas através das ferramentas disponíveis (Enquete, T-Twitter, T-Chat, T-Mail); tendo também os alunos acesso aos recursos digitais associados ao domínio do curso. Nessa etapa, os alunos e o professor já estão familiarizados com a forma de interagir com a tecnologia para TV Digital, se concentrando nos recursos disponibilizados pelos professores a cada atividade. De acordo com Merinhos e Osório [9] é nessa fase, que o papel do moderador é crucial na ajuda e orientação dos participantes para alcançarem a construção da aprendizagem em colaboração.

O modelo, nessa fase, propõe desenvolver recursos que possibilitem que os alunos busquem e tenham acesso às informações. Para isso, é necessário a criação de ferramentas que permitam disponibilizar recursos digitais, tais como vídeos, recursos multimídias e softwares em geral.

A terceira etapa termina quando os participantes aprendem a encontrar e trocar informações de forma produtiva e afetiva, mediante a realização de atividades nas quais é mínima a quantidade de pessoas que participa passivamente.

\subsubsection{Construção do Conhecimento}

Nesta etapa, espera-se que os participantes utilizem as potencialidades da comunicação assíncrona através da TV Digital, onde as interações entre os alunos propiciarão a construção do conhecimento. Um aluno poderá dedicarse ao curso no momento em que lhe for mais apropriado. Como foi dito anteriormente, a forma de utilizar a TV Digital para educação não está disponível a todo tempo, uma vez que se faz necessária a disponibilização das emissoras do conteúdo educativo; Como até o momento não ficou definido de que forma isso será disponibilizado, espera-se que ocorra, no mínimo, como ocorre hoje em dia em que, alguns horários são exclusivos para programas educativos, cabendo então neste momento a possibilidade de envio desses aplicativos interativos para o settop-box. No entanto, deve ficar claro que a potencialidade é muito maior do que hoje é feito, poderíamos ter canais 
específicos só para educação, mas dependemos da boa vontade das emissoras e das políticas públicas que exijam que de fato o decreto 4901 se cumpra [4].

Nessa etapa, é necessário realizar atividades que promovam debates, confronto de pontos de vista, reflexão, raciocínio critico, criatividade e interação entre os alunos. As interações serão realizadas através das ferramentas T-Twitter e T-Chat;

Dentro desse contexto, é necessário trabalhar com atividades colaborativas motivadas pelos professores, mas que o resultado seja do grupo. As atividades têm como finalidade a construção de conhecimentos a partir da colaboração entre os participantes [13].

\subsubsection{Conexão e Desenvolvimento}

Nesta fase, os elementos do grupo tornam-se responsáveis pela sua própria aprendizagem e de seu grupo.

É uma etapa dominada pela criatividade, pela crítica do grupo, pela auto-reflexão, além de proporcionar a cada membro do grupo a possibilidade da fixação do conhecimento adquirido.

O trabalho do aluno é direcionado para o fechamento das construções realizadas com conexões em relação ao domínio da disciplina.

De acordo com o modelo proposto para TV Digital, foram desenvolvidas ferramentas que proporcionam o fechamento do aprendizado, realizadas através de ferramentas de avaliação, tais como enquetes (T-Enquete), ferramenta TV Quiz (Figura 10) e outras que serão desenvolvidas, tais como o uso de mapas conceituais ( $\mathrm{T}$ Mapa).

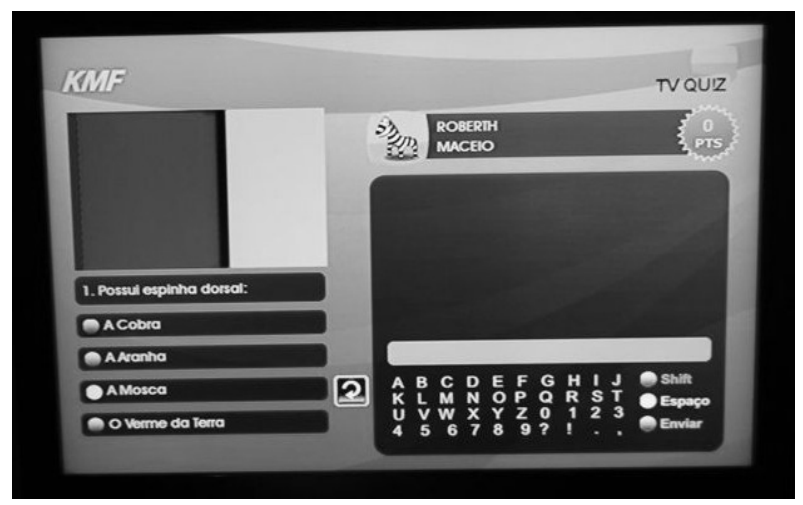

Figura 10: A ferramenta TVQUIZ do A-TVDBR

\subsection{Arquitetura associada ao Modelo A-TVDBR}

A partir da caracterização dos elementos que compõem cada etapa do modelo A-TVDBR, juntamente com as ferramentas envolvidas, foi possível obter uma arquitetura. O modelo A-TVDBR considera cinco etapas. Na Figura 11, apresentam-se as camadas da arquitetura e componentes (ferramentas) envolvidos que possibilitarão a realização das atividades em cada etapa.

A notação da UML[2] foi utilizada para a realização da modelagem do A-TVDBR por se tratar de uma linguagem para modelagem de sistemas orientados a objetos, além de facilitar a comunicação de todas as pessoas envolvidas no processo de desenvolvimento de um sistema.

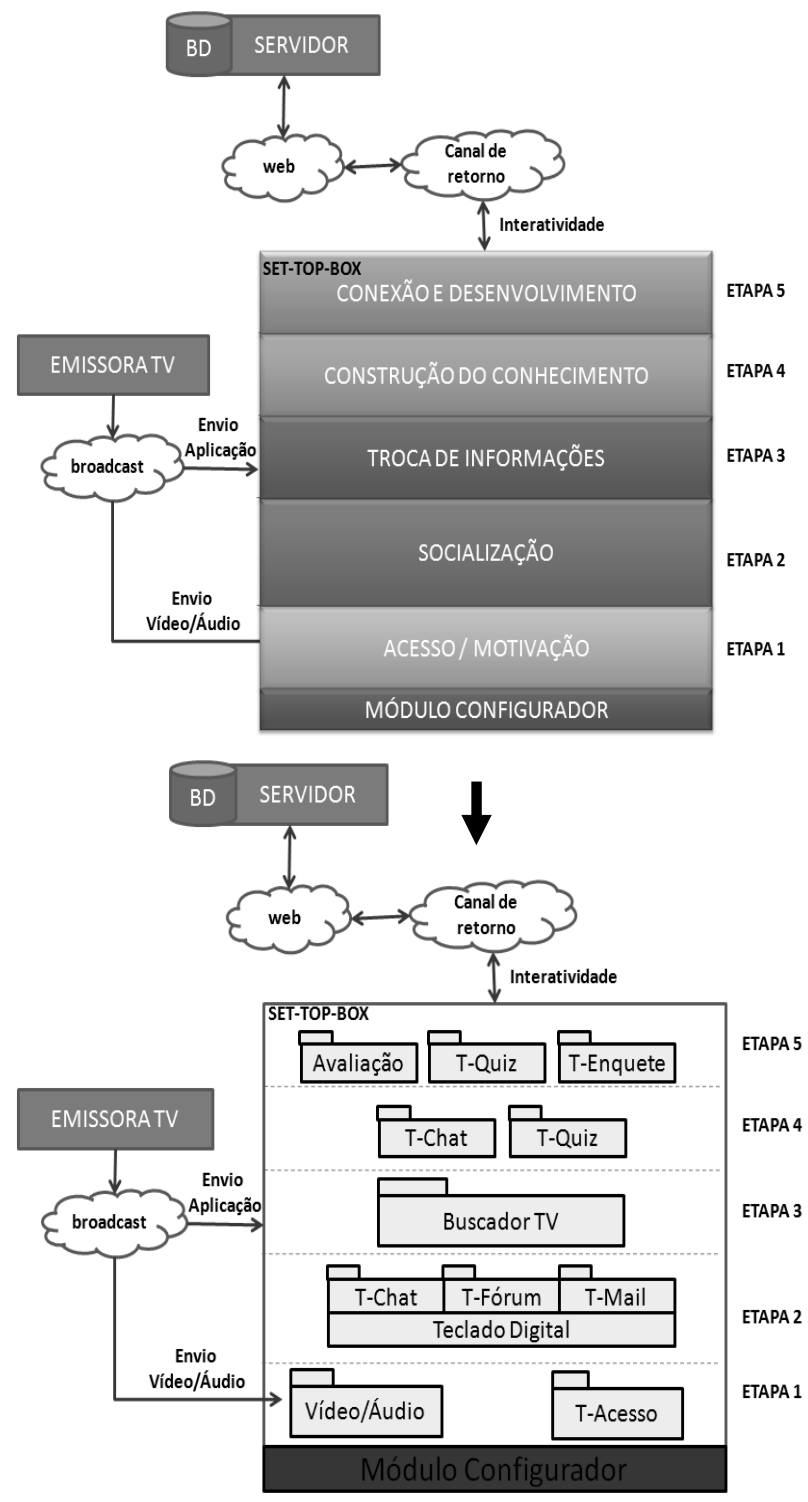

Figura 11: Arquitetura do modelo A-TVDBR. 


\section{Modelagem dos Componentes da Arquitetura do Modelo A-TVDBR}

Os componentes das etapas da arquitetura (Figura 11) do modelo A-TVDBR foram especificados utilizando a UML.

$\mathrm{O}$ diagrama de componentes associado à etapa 2 do modelo A-TVDBR é apresentado na Figura 12.

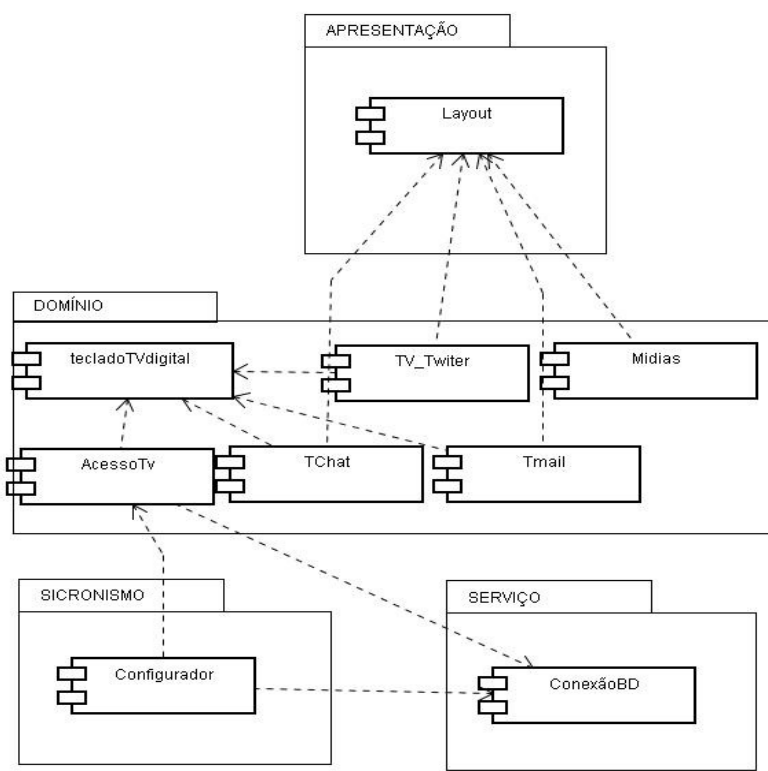

Figura 12: Diagrama de componentes associados à etapa 2 do modelo A-TVDBR.

A modelagem dos componentes, T_Acesso (ou Acesso_TV) e TV_Twiter (Fórum) é apresentada através dos diagramas de classes nas Figuras 13 e 14, respectivamente.

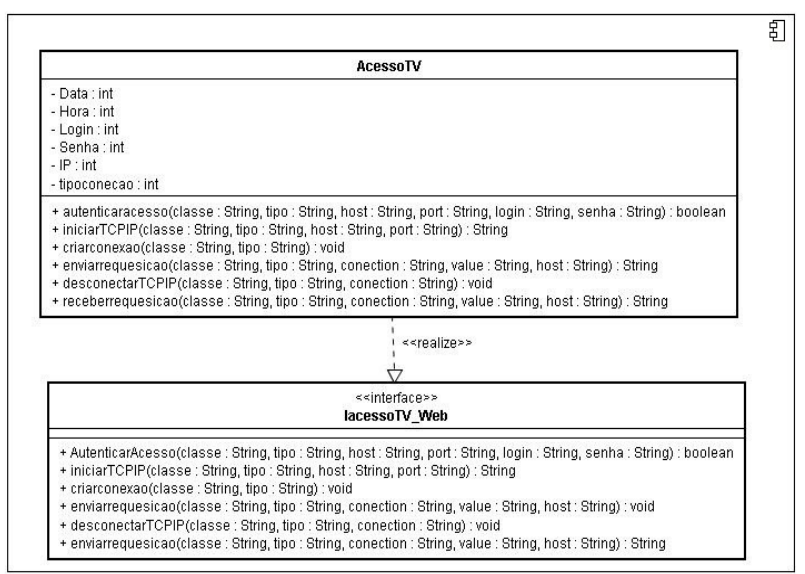

Figura 13: Modelagem do componente Acesso_TV Fórum - Diagrama de classes.
O componente AcessoTV permitirá o tele participante entrar em uma área restrita através de sua autenticação que será feita diretamente utilizando-se da TV Digital. Vale salientar que a validação ocorrerá através do canal de retorno a um servidor remoto.

Já o componente TV_Twiter (Fórum) permitirá, através da autenticação, o envio e o recebimento de comentários para o Twitter, assumindo o papel do fórum. O grande diferencial é que ele possibilitará o armazenamento direto no Twitter, permitindo e democratizando eventuais consultas nas redes sociais.

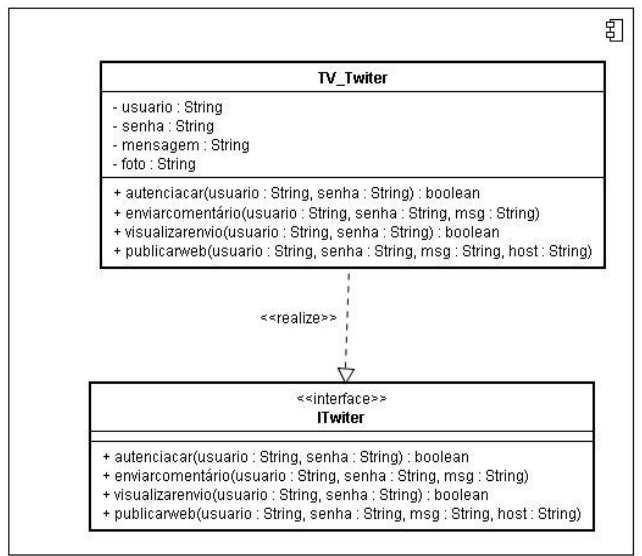

Figura 14: Modelagem do componente TV_Twiter ou Fórum Diagrama de classes.

Componente Teclado é considerado um dos principais componentes. Possibilita, através de um teclado virtual, que pessoas com o controle remoto (composto basicamente de números) consigam realizar envio de textos através da TV Digital. Esse componente está presente e associado a diversos componentes anteriormente descritos.

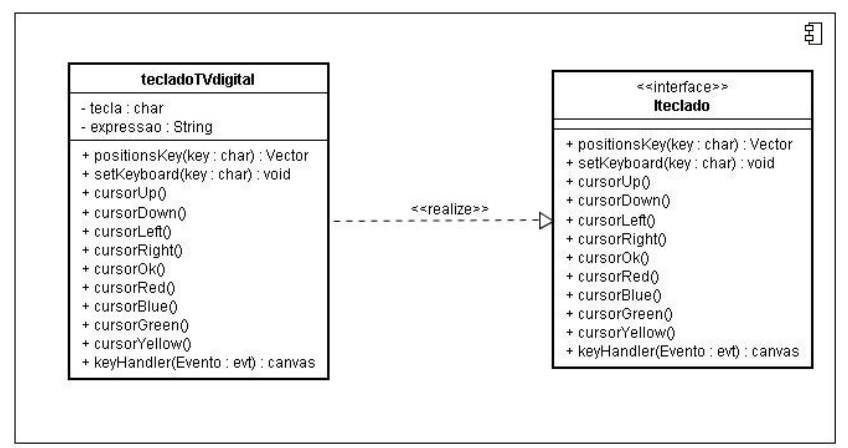

Figura 15: Modelagem do componente Teclado TV digital- Diagrama de classes.

Componente layout Este é um componente que trata do posicionamento das telas e do controle delas exibida na TV Digital. 


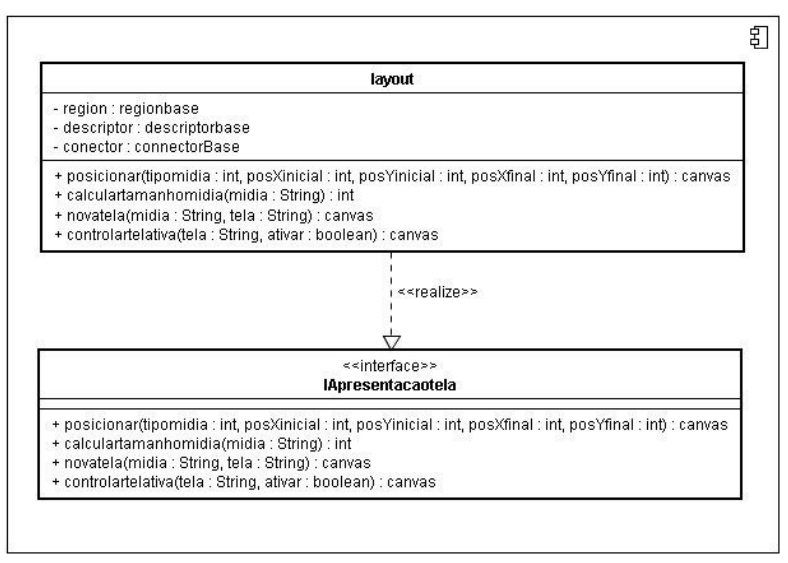

Figura 16: Modelagem do componente Layout- Diagrama de classes.

Componente Enquete, permite o cadastramento, a alteração e a exclusão das enquetes que serão publicadas através do set-top-box. Gerencia as respostadas associadas ao clique de determinado botão gerando um contador do que foi votado.

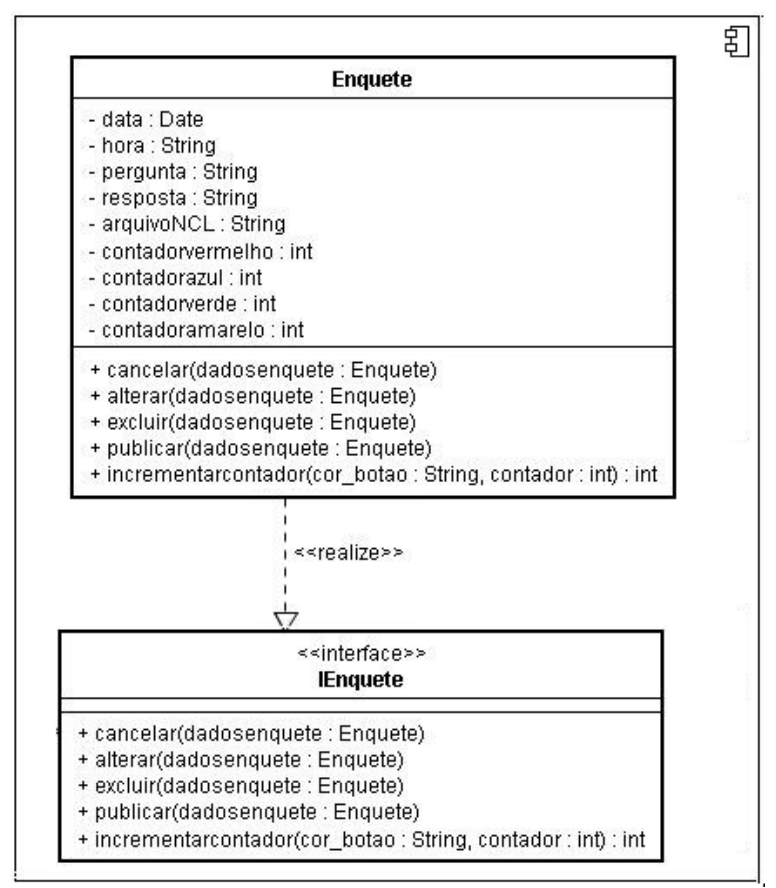

Figura 17: Modelagem do componente Enquete - Diagrama de classes.

\section{Implementação e Aplicação do Modelo A-TVDBR}

A aplicação foi desenvolvida para GINGA-NCL utilizando-se da linguagem declarativa NCL (Nested Context Language) juntamente com código LUA, por se tratar de uma linguagem de fácil aprendizado que combina sintaxe procedural com declarativa, utilizando-se de poucos comandos primitivos. Corroborando-se para o desenvolvimento de uma aplicação leve, muito eficiente e de alto grau de portabilidade para o armazenamento dos dados da interatividade, utilizou-se o banco de dados MySql, sendo instalado o servidor Apache para interpretação dos arquivos PHP.

Para demonstração da aplicação em funcionamento, foi montado um ambiente composto de uma TV LCD com tela de 42 (quarenta e duas) polegadas widescreen, ligada a um set-top-box com acesso a internet.

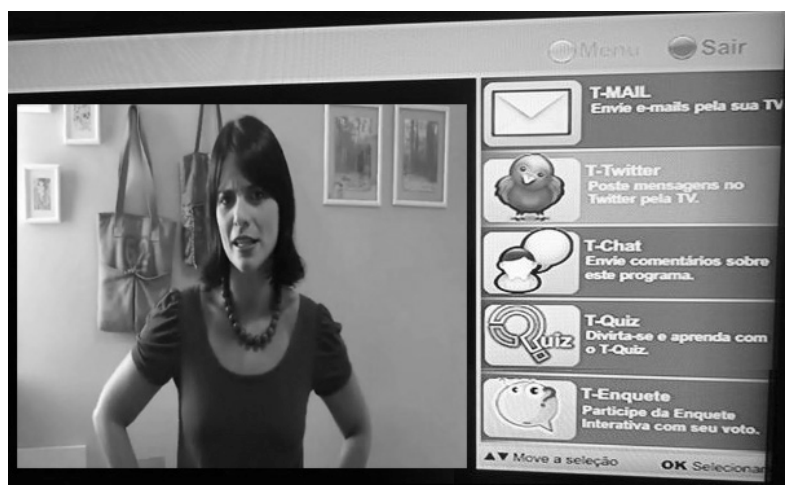

Figura 18: Aplicação desenvolvida baseada no Modelo A-TVDBR.

A aplicação desenvolvida (Figura 18) foi utilizada no contexto de uma experimentação, objetivando verificar se o modelo A-TVDBR, é útil ou não para um grupo de alunos, portadores de deficiências físicas que possuem limitação motora.

A experimentação foi realizada na Associação dos Deficientes Físicos do Estado de Alagoas (ADEFAL). Para tal, utilizou-se a estrutura física da instituição, onde foi possível a participação de vários deficientes físicos que possuem limitações motoras e alguns com deficiência mental leve que tiveram suas coordenações motoras parcialmente afetadas.

Foi proposto a utilização de dois ambientes que conterão o mesmo conteúdo de aprendizagem predefinido pela instituição. O primeiro ambiente será disponibilizado para a metade do grupo denominado grupo controle. Um grupo terá acesso a um ambiente virtual de aprendizagem web (MOODLE). Para o outro grupo, denominado grupo experimento será disponibilizada a TVDIGITAL como ferramenta de aprendizagem. Ambos os ambientes seguiram as cinco etapas propostas pelo modelo de Gilly Salmon [12].

A ideia de trabalharmos com dois grupos diferentes composto de deficientes físicos de membros superiores, se deu pela necessidade de produzirmos uma mostra sem influência anterior de um conhecimento prévio. 
Os dois grupos eram formados por pessoas que possuíam nível de escolaridade de ensino médio sendo um quarto dos participantes do sexo feminino, com a faixa etária entre 21 a 55 anos.

O tema escolhido para os dois ambiente foi: "como conquistar clientes", uma vez que existe uma necessidade muito grande de inserir as pessoas com deficiência no mercado de trabalho.

\subsection{Resultados Obtidos}

Ao aplicarmos o modelo A-TVDBR tendo como alunos os portadores de deficiência física da Associação dos Deficientes Físicos do Estado de Alagoas, verificou-se que o modelo A-TVDBR teve uma contribuição significativa, pois foi percebido na experimentação um aprendizado gradativo através da participação e interação dos alunos no decorrer das cinco etapas realizadas, principalmente no que se refere ao aprendizado gradual na medida em que as etapas são avançadas.

Pode-se perceber, nos alunos do grupo experimental, que o tempo requerido para o uso correto dessa nova tecnologia foi mínimo, comparado ao uso do Moodle (AVA na web) pelos alunos do grupo de controle, pois como mencionado anteriormente, o conhecimento da ferramenta já estava implícito uma vez que os alunos já utilizam a TV convencional, onde a grande diferença é o acréscimo de quatro botões coloridos.

Com relação ao aprendizado, ficou claro também que o conteúdo, ministrado através de vídeo/áudio e utilizando-se de interatividade através da TVDIGITAL brasileira, foi muito produtivo, uma vez que os participantes interagiram em todas as atividades de uma maneira superior em relação às ferramentas utilizadas na web. Verificou-se ainda que o desempenho foi de $83,75 \%$ de acertos dos questionários aplicados via TV-QUIZ. Vale salientar que o mesmo questionário foi aplicado no experimento web, obtendo $65,25 \%$ de acertos.

\section{Conclusão}

Comparado ao modelo do Gilly Salmon [12], o modelo A-TVDBR, apresentado neste trabalho, possibilita que as atividades sejam utilizadas em outros meios que não especificamente a web, permitindo que atividades de ensino e aprendizagem possam ser disponibilizadas para todos os públicos no contexto de um curso ou formação a distância, contribuindo para que o aprendizado ocorra sem a necessidade do aluno se deslocar da sua residência e sim através da tecnologia da TV Digital Brasileira, o que para o deficiente físico será de grande utilidade, assim como para qualquer aluno que precise do estudo a distância.

Vivemos em um país de extensão continental, onde parte da população sofre com a deficiência ou até mesmo a inexistência da educação. Em muitos municípios de vários Estados do país, o acesso às novas tecnologias é muito escasso, limitado, muitas vezes, apenas, a um aparelho de televisão. O próprio governo, ao definir as normas do SBTVD-t, através do artigo 4.901, define, dentre outras coisas, que o objetivo é promover a inclusão social e a diversidade cultural, além de propiciar a criação da rede universal de educação a distância.

No contexto das pessoas portadoras de deficiências físicas, percebe-se que as dificuldades são muito maiores em relação ao deslocamento a uma sala de aula. O modelo A-TVDBR apresentado neste trabalho representa uma iniciativa que possibilite a inclusão social dos deficientes físicos que possuam limitação motora, facilitando o acesso deles a um curso ou formação através da TV Digital, permitindo o aprendizado, utilizando-se apenas de sua TV em um ambiente supostamente ideal que é a sua própria residência.

\section{Referências}

[1] Andreata, Jomar A. InteraTv: um portal para aplicações colaborativas em TV Digital Interativa utilizando a plataforma MHP, dissertação de mestrado Universidade Federal de Santa Catarina, 2006, Florianópolis-SC. Disponível em:< www.das.ufsc.br/ montez/publications/2006\%20 Jomar.Andreata.pdf>

[2] Booch, Grady; Rumbaugh, James; Jacobson, Ivan. UML: Guia do Usuário. 2. ed. São Paulo: Campus, 2005. 474 p.

[3] Batista, C. E. C. F. ; Araújo, T. M. U. ; Omaia, D. ; Anjos, T. Curvelo; Castro, G. M. L. ; Brasileiro, F. V. ; Souza Filho, G. L. Tvgrid: A Grid Architecture To Use The Idle Resources On A Digital Tv Network. Anais Do 7th Ieee International Symposium On Cluster Computing And The Grid (Ccgrid '07). Rio De Janeiro, 2007. Disponível em: < http://www.lavid.ufpb.br/ curvelo/papers/tvgrid_-_ccgrid07.pdf $>$.

[4] Brasil; Decreto n 4.901, de 26 de novembro de 2003. Institui o Sistema Brasileiro de Televisão Digital - SBTVD. Disponível em: $<$ http://www.planalto.gov.br/ccivil_03/ Decreto/2003/D4901.htm>.

[5] Castro, D. "Cai audiência de TV entre mais ricos 
e adolescentes", Folha de São Paulo, 2008, disponível em : <http://www.direitoacomunicacao. org.br/index2.php?option=com_content \&task=vi ew\&id $=2477 \&$ pop $=1 \&$ page $=0>$.

[6] Filho, A.; Castro, C. O caso brasileiro de TV Digital e a proposta de nova plataforma de comunicação para os países emergentes. 2005. Disponível em: <http://reposcom.portcom. intercom.org.br/bitstream/1904/16761/1/R19224.pdf $>$

[7] Ginga (2008) "TV Interativa se faz com Ginga", disponível em : <http://www.ginga.org.br/>.

[8] KIT (2008). Kiingston Interactive Television. Disponível em: <http://www.kitv.co.uk >

[9] Meirinhos M. e Osório A.; Modelos de Aprendizagem em Ambientes Virtuais, 2007, Instituto Politécnico de Bragança editora: Universidade do Minho Nónio. Disponível em: < http://bibliotecadigital.ipb.pt/bitstream/10198/ 399/1/Comuni_Modelos_M_O.pdf >

[10] Moodle. URL: http://moodle.org, último acesso em agosto/2009

[11] Pimentel, Carolina. Ministério da Educação lança o TV Escola Digital Interativa. Agência Nacional. Brasília. Disponível em: $<$ http://www.idbrasil.gov.br/noticias/News_Item. 2003-12-16.5818/view >.

[12] Salmon, G., E-tivities: Key for active online learning. Reino Unido : Kogan Page, 2002.

[13] Salmon, G., E-actividades: El factor clave para una formación en linea activa, Colección Educación y Sociedad Red, Barcelona, editora UOC, 2004.

[14] Tavares, Tatiana Aires; Santos, Celso Alberto Saibel; Assis, Thiago Rocha de, Pinho, Clarissa Braga Bittencourt de; Carvalho, Germano Mariniello de; Costa, Clarissa Santana da; A TV Digital Interativa como Ferramenta de Apoio à Educação Infantil. Revista Brasileira de Informática na Educação, v.15, nº 2. maio/ago, 2007.

[15] TIC Domicílios e usuários 2008, Pesquisa sobre o Uso das Tecnologias da Informação e da Comunicação no Brasil TIC Domicílios e TIC Empresas 2008 São Paulo : Comitê Gestor da Internet no Brasil, 2009. Disponível em: $<$ http://hal.ceptro.br/cgi-bin/indicadores-cgibr008 ? pais $=$ brasil\&estado $=$ al\&academia $=$ acade mia\&age $=$ de $-35-a-44-$ anos\&education $=$ posmestrado\&purpose $=$ pesquisa-academica $>$.
[16] Vavassori, Fabiane B. Raabe, André L. Organização de atividades de aprendizagem utilizando ambientes virtuais: um estudo de caso In: Silva, Marcos(org.). Educação online. São Paulo: Edições Loyola, 2003

[17] Véras, Douglas et al. Uma Arquitetura para Integrar Ambientes Educacionais na Web com Sistemas em T-Learning. In: SIMPÓSIO BRASILEIRO DE INFORMÁTICA NA EDUCAÇÃO, 20., 2009, Florianópolis. Anais. Florianópolis: Congresso Brasileiro de Computação, 2009. Disponível em: <http://wwwexe.inf.ufsc.br / sbie2009/anais/conteudo/artigos/completos/61 789_1.pdf>. Acesso em: 20 dez. 2011.

[18] Vicari, Rosa Maria; SILVA, Júlia Marques Carvalho da. Relacionando a Televisão Digital Interativa com o conceito de Objetos de Aprendizagem: conceitos, aspectos históricos, e perspectivas. In: SIMPÓSIO BRASILEIRO DE INFORMÁTICA NA EDUCAÇÃO, 20., 2009, Florianópolis. Anais. Florianópolis: Congresso Brasileiro de Computação, 2009.Disponível em: $<$ http://wwwexe.inf.ufsc.br/ sbie2009/anais/cont eudo/artigos/completos/61891_1.pdf>. Acesso em: 20 dez. 2011. 